\title{
Psychological determinants of the intention to educate patients about benzodiazepines
}

\author{
Geeske Brecht Ten Wolde $\cdot$ A. Dijkstra \\ P. Van Empelen · A. Knuistingh Neven • \\ F. G. Zitman
}

Received: 1 February 2007 / Accepted: 26 November 2007 / Published online: 18 December 2007

(C) The Author(s) 2007

\begin{abstract}
Objective General practitioners and pharmacists do not properly educate their patients about the disadvantages of benzodiazepines. In order to increase and improve education, this study will investigate which psychological factors (i.e., beliefs, outcome expectation, social norm and self-efficacy) predict the intention to educate. Methods A cross-sectional survey study was conducted in which 339 general practitioners and 149 pharmacists in the Netherlands completed a questionnaire. Results The Results show that the above-mentioned factors play an important role in forming intentions to educate. However, differences exist between general practitioners and pharmacists. Conclusion General practitioners and pharmacists intend to educate in cases where they think that benzodiazepines have well-defined disadvantages, when the education they undertake leads to success, when they feel pressure to educate from their surroundings and when they are capable of educating. Implications for practice These findings contribute to a better understanding of patient
\end{abstract}

G. B. Ten Wolde $(\bowtie) \cdot$ P. Van Empelen

Department of Clinical and Health Psychology, Leiden University, Wassenaarseweg 52, P.O. Box 9555, 2300 RB

Leiden, The Netherlands

e-mail: tenwolde@fsw.leidenuniv.nl

\section{A. Dijkstra}

Department of Social and Organizational Psychology, University of Groningen, Groningen, The Netherlands

\section{A. Knuistingh Neven}

Department of Public Health and Primary Care, Leiden

University Medical Center, Leiden, The Netherlands

F. G. Zitman

Department of Psychiatry, Leiden University Medical Center, Leiden, The Netherlands education and are of great value in developing new interventions to improve education.

Keywords Benzodiazepine use - General practitioner · Netherlands · Patient education · Pharmacist .

Psychological factors

\section{Impact of findings on practice}

- Our findings will result in a better understanding of patient education about the disadvantages of benzodiazepine use.

- Our results can be used to develop new interventions to improve education about benzodiazepine use.

\section{Introduction}

Benzodiazepines are commonly prescribed drugs aimed at the short-term relief of severe, disabling anxiety or insomnia. The use of benzodiazepines has only been proven effective when used short term [1-5]. Long-term use is not only non-effective, it can even be problematic because it is related to several negative health effects such as addiction, falls, hip fractures, phases of depression and impaired cognition [6-17]. Because of this, guidelines for general practitioners have been established, for example, by the Dutch College of General Practitioners (NHG) regarding how and when to prescribe benzodiazepines to patients. Benzodiazepines for sleep disorders, for instance, are recommended for at most 10-14 days [18].

Despite these recommendations, $10-15 \%$ of the population uses benzodiazepines on a regular basis, and 3\% uses them chronically [19]. The elderly are the most common 
users: $42 \%$ of all users are 65 or older. They take 2.9 times more benzodiazepines than their younger counterparts. Those who are 75 years or older take even four times as much $[20,21]$. The number of prescriptions for benzodiazepines in 2003 was almost eleven million and continues to grow by $1 \%$ each year $[22,23]$. In addition, other European and non-European countries like the United States have to contend with widespread use of benzodiazepines [24]. Given the long-term adverse effects of benzodiazepine use and the high costs associated with the high number of prescriptions, it is essential that both prescriptions for benzodiazepines be reduced and that patients be well informed about the (in)effectiveness and (adverse) effects of long-term benzodiazepine use.

The latter is often lacking: it is known that the education offered by health practitioners to patients is often inadequate and that alternatives like counselling or referral to other services are not offered in most instances [25, 26]. Two groups can be distinguished in patient education: general practitioners and pharmacists. Although they have different roles, they are both responsible for informing and educating patients about the use of drugs. In the Netherlands pharmacists and general practitioners need to comply with the same law of medicine [27].

Today, it is known that education about the disadvantages of benzodiazepine use is often non-existent: $80 \%$ of prescription refills are handed out by the assistant instead of general practitioners seeing the patient themselves [22]. As a result, most patients are not educated at all. This is surprising because education would result in more satisfied patients, along with a better understanding of the pros and cons of medication, and more compliance to treatment [28-30]. It is also known that when they do educate, general practitioners and pharmacists can play a vital role in changing patients' attitudes towards medicine use. For instance, it has been shown that pharmacists can play an important role in changing the drug attitudes of depressive patients [31]. Thus, we can conclude that educating by both general practitioners and pharmacists the benzodiazepine user can have positive results in terms of the goal of reducing the amount of benzodiazepines.

But why is it that general practitioners and pharmacists do not educate their patients well? In case of general practitioners on the one hand, it is known that they lack the time [30, 32-34]. In addition to this, the workload of the general practitioner is even higher when health problems are psychological or social in nature, as these problems take up more time than physical problems $[35,36]$. This is the case with benzodiazepines: the reasons why patients start taking benzodiazepines mostly stem from stress, trauma or acute anxiety [30]. High prescription levels of benzodiazepines are also related to the uncertainty of general practitioners about suggesting alternatives [30, 37]. And they are unwilling to raise the issue of benzodiazepine withdrawal because they view an intervention as pointless [30]. Although pharmacists, on the other hand, are eager to undertake an extended role in health education, it is still uncommon for them to educate their patients, like drawing attention to leaflets displayed, or to actively provide patients with verbal education. Besides this, they are not always certain in educating patients about the effects and possible disadvantages of drugs in general [38, 39]. In order to stimulate patient education by both general practitioners and pharmacists about benzodiazepine use it is important to develop an intervention that is based on the psychological causes behind educating behaviour. It is important, therefore, for an intervention to be developed that targets these psychological causes related to educating patients.

Behaviour change-from not educating patients to educating them properly-starts with the formulation of the intention to educate. Intentions to perform specific behaviours have been shown to be the most powerful psychological predictors of actual behaviour [40, 41]. To distil the psychological determinants of the intention to educate, we will make use of psychological determinants derived from different models (i.e., Theory of Planned Behaviour [42], Protection Motivation Theory [43], and Social Cognitive Theory [44]). These models have been shown to have good predictive value in a diversity of behaviours such as individual health behaviour like tobacco use [45] and drinking behaviour [46, 47], but also in predicting behaviour of individuals at other societal levels such as teachers providing sex education [48] or predicting the intention to vote for law enforcement by politicians [49]. The above models all acknowledge that intention is the most proximal determinant of behaviour and that intention is in turn predicted by beliefs, outcome expectations (positive and negative), social norm and selfefficacy. Therefore, the aim of this study is to assess the psychological factors that predict the intention of general practitioners and pharmacists to educate their patients about benzodiazepine use.

\section{Method}

Participants and design

A cross-sectional survey study was conducted in order to assess the psychological determinants of intention to educate by general practitioners and pharmacists. Addresses of general practitioners and pharmacists were selected from an electronic version of the Dutch telephone directory. In total 999 general practitioners and 605 pharmacists were 
randomly chosen. Surveys were then sent to these general practitioners and pharmacists.

\section{Questionnaire}

The questionnaire assessed demographic data such as age, the amount of time the general practitioners and pharmacists were active in their profession, the number of patients they had in their files, and the number of prescriptions were handed over.

Intention, beliefs, outcome expectations, social norm and self-efficacy were measured on a five-point scale: 'definitely not' [1], 'probably not' [2], 'neutral' [3], 'probably yes' [4], and 'definitely yes' [5]. Intention was measured with two questions. The two questions were: 'In the next 12 months are you planning to educate patients who start taking benzodiazepines or renew their use, about the disadvantages of benzodiazepines?' and 'In the next 12 months are you planning to educate patients who are already taking benzodiazepines?'.

Beliefs, outcome expectations, social norm and selfefficacy were measured as follows. The beliefs regarding benzodiazepine use were response-efficacy and disadvantages. Response-efficacy was measured with two items, for example, 'Benzodiazepines are not effective'. Disadvantages were measured by three items. One example was 'Patients who use benzodiazepines for more than 3 months become addicted to them'. The psychological factors towards patient education were outcome expectations, social norm and self-efficacy. Positive outcome expectations were measured by three items. One item was 'If I educate my patients about the disadvantages of benzodiazepines, they will benefit from that'. Negative outcome expectations were also measured by means of three items. One example was 'If I educate my patients about the disadvantages of benzodiazepines, this will present a risk for the doctor-patient relationship'. Three items refer to social norm. One example is 'Do you think that KNMP (Royal
Dutch Pharmaceutical Society, an association for and by pharmacists in the Netherlands) or NHG (Dutch College of General Practitioners) expects you to educate about benzodiazepines'. Lastly, self-efficacy was measured by one item 'It is difficult to educate patients about the disadvantages of benzodiazepines' (recoded).

\section{Results}

A total of 339 general practitioners (34\%) and $149(25 \%)$ pharmacists completed and returned the questionnaires. The mean age of the general practitioner was 48.5 years and that of the pharmacist was 39 years. Their average practice experience was 17.3 and 12.5 years respectively. An average of 2,545 patients were enrolled at the general practice. At the pharmacy, there were 10,037 patients with 80,653 prescriptions dispensed per year.

Reliability analyses showed that Cronbach's Alpha's were low to high: intention ( 2 items, $\alpha=0.66$ ), responseefficacy ( 2 items, $\alpha=0.76$ ), disadvantages ( 3 items, $\alpha=$ 0.62 ), positive outcome expectations (3 items, $\alpha=0.75$ ), negative outcome expectations ( 3 items, $\alpha=0.63$ ), and social norm ( 3 items, $\alpha=0.58$ ).

Table 1 gives a summary of the differences in mean scores and standard deviations on the psychological factors between general practitioners and pharmacists. $T$-tests were conducted to examine differences between the psychological factors of general practitioners and pharmacists. Significant differences were found for intention $(t(478)=$ $12.1 ; P<0.001)$, negative outcome expectations $(t(476)=$ $2.8 ; P<0.05)$, social norm $(t(476)=4.0 ; P<0.001)$ and self-efficacy $(t(471)=4.5 ; P<0.001)$. These differences suggest that general practitioners have a more positive intention $(95.5 \%$ of the general practitioners were intending to educate in contrast to $72.1 \%$ of the pharmacists), that they expect more negative outcomes when they do educate, that they experience a more positive social norm and that they feel more capable of educating their patients than do

Table 1 Differences in mean scores (M) and standard deviations (SD) on the psychological factors between general practitioners and pharmacists

\begin{tabular}{|c|c|c|c|c|c|c|c|}
\hline & \multirow[t]{2}{*}{ Items } & \multicolumn{2}{|c|}{ General practitioner } & \multicolumn{2}{|c|}{ Pharmacist } & \multirow[t]{2}{*}{$t$} & \multirow[t]{2}{*}{$P$} \\
\hline & & Range & $\mathrm{M}(\mathrm{SD})$ & $\mathrm{M}(\mathrm{SD})$ & $\mathrm{df}$ & & \\
\hline Intention & 2 & $1-5$ & $4.0(0.8)$ & $3.1(0.8)$ & 478 & 12.1 & $<.001$ \\
\hline Response-efficacy & 2 & $1-5$ & $4.1(1.0)$ & $4.0(1.1)$ & 477 & .7 & .48 \\
\hline Disadvantages & 3 & $1-5$ & $4.3(0.7)$ & $4.3(0.7)$ & 478 & .4 & .69 \\
\hline Positive outcome expectation & 3 & $1-5$ & $2.5(0.8)$ & $2.4(0.9)$ & 477 & -1.1 & .28 \\
\hline Negative outcome expectation & 3 & $1-5$ & $2.5(1.0)$ & $2.2(1.0)$ & 476 & 2.8 & $<.05$ \\
\hline Social norm & 3 & $1-5$ & $3.8(0.8)$ & $3.5(0.8)$ & 476 & 4.0 & $<.001$ \\
\hline Self-efficacy & 1 & $1-5$ & $1.9(1.1)$ & $2.4(1.0)$ & 471 & 4.5 & $<.001$ \\
\hline
\end{tabular}


Table 2 Regression of intention on the psychological factors for general practitioners and pharmacists

\begin{tabular}{|c|c|c|c|c|c|c|}
\hline & \multicolumn{6}{|c|}{ Intention to educate } \\
\hline & \multicolumn{3}{|c|}{ General practitioner } & \multicolumn{3}{|c|}{ Pharmacist } \\
\hline & B & $P$ & $R^{2}(F)$ & $\beta$ & $P$ & $R^{2}(F)$ \\
\hline $\begin{array}{l}\text { Response- } \\
\text { efficacy }\end{array}$ & .02 & .75 & $.15(9.8)$ & .06 & .53 & $.22(6.1)$ \\
\hline Disadvantages & .27 & .00 & & .12 & .19 & \\
\hline $\begin{array}{l}\text { Positive } \\
\text { outcome } \\
\text { expectation }\end{array}$ & -.01 & .87 & & .19 & .03 & \\
\hline $\begin{array}{l}\text { Negative } \\
\text { outcome } \\
\text { expectation }\end{array}$ & -.11 & .03 & & -.07 & .36 & \\
\hline Social norm & .12 & .03 & & .23 & .01 & \\
\hline Self-efficacy & -.14 & .01 & & .12 & .17 & \\
\hline
\end{tabular}

pharmacists. They did not differ significantly on both sets of beliefs on the effects of benzodiazepines (response efficacy and disadvantages), nor on positive outcomes they expect from educating patients.

Separate regression analyses were conducted for general practitioners and pharmacists whereby intention was regressed on response efficacy, disadvantages, outcome expectations (positive and negative), social norm and selfefficacy (Table 2). For the general practitioners, the regression of intention to educate explained a variance of $R^{2}=0.15$, with disadvantages, negative outcome expectations, social norm and self-efficacy being significant determinants. When we looked at the pharmacists, the regression yielded an $R^{2}$ of 0.22 , with only positive outcome expectations and social norm being significant determinants. Thus, general practitioners' intention to educate was higher when they saw more disadvantages from benzodiazepine use, when they expected less negative outcomes from their education, when they perceived more social pressure to educate, and when they thought they were more capable of educating. Pharmacists' intention to educate was higher, on the other hand, when they saw more positive outcomes for their education efforts, and when they perceived more social pressure to educate.

\section{Discussion}

In the present study predictors of intended benzodiazepine education were examined among general practitioners and pharmacists. The main findings were that beliefs, outcome expectations (positive and negative), social norm and selfefficacy played a role in forming intentions to educate. However, differences existed among practitioners. In the case of general practitioners, intention was predicted by beliefs, negative outcome expectations, social norm and self-efficacy, whereas intention of pharmacists to educate was only predicted by positive outcome expectations and social norm. These findings suggest that when persuading/ reinforcing general practitioners and pharmacists to educate, different information needs to be provided to each group in order to ensure patient education.

A possible explanation for the differences found between general practitioners and pharmacists is the fact that general practitioners are actually educating on a daily basis, while this is not the case with pharmacists. In the present study, $91 \%$ of the general practitioners indicated that they educated their patients when these started taking benzodiazepines, contrary to $47 \%$ of the pharmacists. In the Netherlands pharmacists, unlike general practitioners, are since July 2007 under an obligation to educate [27]. As such, the differences in psychological determinants found may be related to the (lack of) experience that general practitioners and pharmacists have regarding patient education. In other words, due to the experience of general practitioners, they are more likely to report the barriers and negative consequences of patient education, while pharmacists, on the other hand, might base their expectations on hypothetical situations, not having experienced the drawbacks of educating patients. Another possibility is that general practitioners have a more personal relationship with their patients than pharmacists have. Thus, general practitioners know the difficulties patients experience in quitting benzodiazepines. Although these explanations are speculative, it seems probable that these differences found would imply practical differences for general practitioners and pharmacists.

\section{Practice implications}

Because it is now known that beliefs, outcome expectations, social norm and self-efficacy are responsible for the intention to educate, this knowledge can be used in order to get the general practitioner and pharmacist to be more motivated in educating their patients. These determinants must now be translated into practical strategies. First of all, in order to get the general practitioners and pharmacists to realise the importance of educating, it is necessary to increase their awareness by extending their knowledge about the desirability of patient education on benzodiazepine use. Beliefs and outcome expectancies can change due to new persuasive arguments, and as a result of the enhancement of the salience of information already possessed and along with linking beliefs with personal values [50]. This can be achieved, for example, by information leaflets, pamphlets, seminars, lectures and so on. From this study, it is particularly important to keep the differences between these two kinds of practitioners in mind. For the general practitioners it is especially 
important to reduce negative outcome expectations by telling them that education will not harm the relationship with others (such as the relationship with the patient or pharmacist) and that education will not require too much time and effort on the long-term. For the pharmacist, on the other hand, it is particularly important to promote the positive outcomes of educating by for example underlining the fact that education will result in less benzodiazepine use, that patients will have a lower risk of falling and that the patient will benefit as a result.

Secondly, methods of influencing social norms are anchored in providing information on group norms [51]. General practitioners and pharmacists are also likely to increase or sustain their education efforts towards benzodiazepine users when important social influences are activated, such as professional federations like the Royal Dutch Pharmaceutical Society and the Dutch Society of General Practice. These federations can put policies into place, which ensure that (recurrent) patient education and monitoring becomes part of daily practice. And finally, methods for selfefficacy enhancement include skills training, mastery experience and modelling. All this must be combined with feedback and reinforcement. It is widely known that in order to increase confidence (i.e., self-efficacy) people need encouragement and successful experiences [52].

The present findings have addressed determinants that need to be targeted in order to facilitate an intervention that ensures patient education of general practitioners and pharmacists. Additional factors such as, for example, environmental factors, need to be formulated in further studies. These will then contribute to a deeper understanding of how benzodiazepine education interventions can be best implemented. Thus, more research is necessary.

Instead of looking at possible solutions for improving the education of general practitioners and pharmacists, it is also important to look at other ways to have patients educated. As has been described elsewhere [35, 53-55], it also turns out in this study, that general practitioners and pharmacists suffer from time constraints: more than $38 \%$ of the respondents think that educating patients takes too much time. For that reason it is important that work be taken off the practitioners' hands. A tool which educates patients automatically would therefore be handy. It is known that writing a standard letter to patients already reduces benzodiazepine intake [56-59]. However, personalized letters produced by a computer program, meaning without even seeing the patient, appear to be even more effective [60].

\section{Limitations}

Caution is warranted in interpreting the results of this study. First, low to high Cronbach's Alphas were found and low variances were found in the scales representing intention to educate and psychological factors predicting intention to educate. This may be due to the fact that the number of items for each factor was limited. This was done intentionally to increase response rate as it is known that health practitioners are not likely to participate [61]. The questionnaire was therefore minimized to attract them. The sample used in this study might also cause a stir. Around $70 \%$ of those who received questionnaires did not respond. However, according to Swanborn, a response rate of $30 \%$ is not bad for this type of research in the Netherlands [62]. Also, it is known that response rates among health practitioners are low due to time constraints, among other things [61]. Also comparing our participants with the Dutch population it is known that a general practitioner in the Netherlands has on average 2,053 patients per practice [63]. According to the Foundation for Pharmaceutical Statistics [22] Dutch pharmacies on average attend to 8,700 patients per pharmacy and process 73,800 prescriptions a year. It thus looks like we were dealing with a representative sample. Most importantly, studies are still important in order to identify common problems in health care systems [64]. This also applies to the present study: it tries to find an answer to why general practitioners and pharmacists do not educate as they should.

\section{Conclusion}

In the present study predictors of intended benzodiazepine education were examined among general practitioners and pharmacists. The main findings were that beliefs, outcome expectations (positive and negative), social norm and self-efficacy played a role in forming intentions to educate. However, differences existed among practitioners. This study is the first Dutch study that has mapped the psychological factors of intention to educate patients about benzodiazepines. A start has thus been made in understanding the motives of general practitioners and pharmacists when it comes to educating.

Acknowledgements We like to thank Kate Pendlington and Tom Leighton for correcting grammar and spelling.

Funding This study was financially supported by the Dutch Council for Health Insurance.

\section{Conflicts of interest None.}

Open Access This article is distributed under the terms of the Creative Commons Attribution Noncommercial License which permits any noncommercial use, distribution, and reproduction in any medium, provided the original author(s) and source are credited. 


\section{References}

1. College voor Zorgverzekeringen. Gebruik van benzodiazepinen 1993-1998 [Use of benzodiazepines 1993-1998]. Geneesmiddelen Informatie Project (GIP-signaal); 2000.

2. Holbrook AM, Cheng C, King D, Crowther R, Lotter A. Metaanalysis of benzodiazepine use in the treatment of insomnia. CMAJ 2000;162(2):225-33.

3. Holbrook AM, Cheng C, King D, Crowther R, Lotter A. The diagnosis and management of insomnia in clinical practice: a practical evidence-based approach. CMAJ 2000;162(2):216-20.

4. Kupfer DJ, Reynolds CF. Management of insomnia. N Engl J Med 1997;336(5):341-6.

5. Lader MH. Limitations on the use of benzodiazepines in anxiety and insomnia: are they justified? Eur Neuropsychopharmacol 2000;9 Suppl 6:S399-405.

6. Ashton $\mathrm{H}$. The treatment of benzodiazepine dependence. Addiction 1994;89:1535-41.

7. Ashton H. Protracted withdrawal symptoms from benzodiazepines. Psychiatr Ann 1995;25:158-65.

8. Ashton $\mathrm{H}$. The diagnosis and management of benzodiazepine dependence. Curr Opin Psychiatry 2005;18(3):249-55.

9. Barker MJ, Greenwood KM, Jackson M, Crowe SF. Persistence of cognitive effects after withdrawal from long-term benzodiazepine use: a meta-analysis. Arch Clin Neuropsychol 2004;19(3): 437-54.

10. Gorgels WJ, Breteler MH, Van de Lisdonk EH, Oude Voshaar RC, Mol AJ, Zitman FG. Het langdurig gebruik van benzodiazepinen [Long-term use of benzodiazepines]. Ned Tijdschr Geneeskd 2001;145(28):1342-6.

11. O'Connor KP, Marchand A, Bélanger L, Mainguy N, Landry P, Savard P, et al. Psychological distress and adaptational problems associated with benzodiazepine withdrawal and outcome: a replication. Addict Behav 2004;29(3):583-93.

12. Salzman C. Addiction to benzodiazepines. Psychiatr Q 1999; 69(4):251-61.

13. Schweizer E, Rickels K, De Martinis N, Case G, Garcia-Espana F. The effect of personality on withdrawal severity and taper outcome in benzodiazepine dependent patients. Psychol Med 1998;28(3):713-20.

14. Wan H, Warburton EC, Zhu XO, Koder TJ, Park Y, Aggleton JP, et al. Benzodiazepine impairment of perirhinal cortical plasticity and recognition memory. Eur J Neurosci 2004;20(8):2214-24.

15. Westra HA, Stewart SH, Teehan M, Johl K, Dozois DJ, Hill T. Benzodiazepine use associated with decreased memory for psychoeducation material in cognitive behavioral therapy for panic disorder. Cogn Ther Res 2004;28(2):193.

16. Kan CC, Breteler MH, Zitman FG. High prevalence of benzodiazepine dependence in out-patient users, based on the DSM-III-R and ICD-10 criteria. Acta Psychiatr Scand 1997; 96(2):85-93.

17. Ashton $\mathrm{H}$. The diagnosis and management of benzodiazepine dependence. Curr Opin Psychiatry 2006;18(3):249-55.

18. Knuistingh Neven A, Lucassen PLBJ, Bonsema K, Teunissen H, Verduin MM, Bouma M. NHG-standaard Slaapproblemen en slaapmiddelen [Sleepproblems and benzodiazepines]. Huisarts Wet 2005;48:402-15.

19. Gezondheidsraad: Kerncommissie MTA. Naar een doelmatig gebruik van benzodiazepines [To an efficient way of using benzodiazepines]. Publicatienummer 1998/20. Den Haag: Gezondheidsraad; 1998.

20. Stichting Farmaceutische Kengetallen. Data \& Feiten [Facts \& figures]. The Hague; 2003.

21. Stichting Farmaceutische Kengetallen. Data \& Feiten [Facts \& figures]. The Hague; 2004.
22. Stichting Farmaceutische Kengetallen. Data \& Feiten [Facts \& figures]. The Hague; 2005.

23. Stichting Farmaceutische Kengetallen. Farmacie in cijfers [Pharmaceutical statistics]. The Hague; 2005.

24. Zandstra SM, Furer JW, Van de Lisdonk EH, Van't Hof HM, Bor $\mathrm{JH}$, Van Weel C, et al. Different study criteria affect the prevalence of benzodiazepine use. Soc Psychiatry Psychiatr Epidemiol 2002;37(3):139-44.

25. Barat I, Andreasen F, Damsgaard EM. Drug therapy in the elderly: what doctors believe and patients actually do. Br J Clin Pharmacol 2001;51(6):615-22.

26. Barter G, Cormack M. The long-term use of benzodiazepines: patients' views, accounts and experiences. Fam Pract 1997;13(6): 491-7.

27. Ministery of Health, Welfare and Sport. Wet op de Geneeskundige Behandelovereenkomst [Law on the agreement of treatment of medicines]. 2007.

28. Di Blasi Z, Georgiou A, Kleijnen J, Harkness E, Ernst E. Influence of context effects on health outcomes: a systematic review. Lancet 2001;357(9258):757-62.

29. Ong LM, Lammes FB, de Haes JC, Hoos AM. Doctor-patient communication: a review of the literature. Soc Sci Med 1995; 40(7):903-18.

30. Parr JM, Kavanagh DJ, Young RM, McCafferty K. Views of general practitioners and benzodiazepine users on benzodiazepines: a qualitative analysis. Soc Sci Med 2006;62(5):1237-49.

31. Brook O, Van Hout H, Nieuwenhuyse H, Heerdink E. Impact of coaching by community pharmacists on drug attitude of depressive primary care patients and acceptability to patients; a randomized controlled trial. Eur Neuropsychopharmacol 2003; 13(1):1-9.

32. Kapur N, Appleton K, Neal RD. Sources of job satisfaction and psychological distress in GPs and medical house officers. Fam Pract 2000;16(6):600-1.

33. Mechanic D. How should hamsters run? Some observations about sufficient patient time in primary care. BMJ 2001;323(7307): 266-8.

34. Commonwealth Fund/Harvard/Harris. The Commonwealth Fund 2000 International Health Policy Survey of Physicians. New York; 2000.

35. Zantinge EM, Verhaak PFM, Bensing JM. The workload of GPs: patients with psychological and somatic problems compared. Fam Pract 2005;22(3):293-7.

36. Deveugele M, Bensing J, De Maeseneer J, Derese A, Van den Brink Muinen A. Consultation length in general practice: cross sectional study in six European countries. BMJ 2002;325(7362): 472 .

37. Dempsey OP, Moore H. Psychotropic prescribing for older people in residential care in the UK, are guidelines being followed? Prim Care Community Psychiatry 2005;10(1):13-8.

38. Van Bergeijk D, Van Geffen ECG, Van Hulten RP. Knelpunten bij voorlichting in de apotheek [Bottlenecks in education at the pharmacy]. University of Utrecht; 2005. ISBN 90-74772-70-6.

39. Bensing JM, Visser A, Saan H. Patient education in The Netherlands. Patient Educ Couns 2001;44(1):15-22.

40. Armitage CJ, Conner M. Efficacy of the theory of planned behaviour: a meta-analytic review. Br J Soc Psychol 2001;40(4): 471-99.

41. Godin G, Kok G. The theory of planned behavior: a review of its applications to health-related behaviors. Am J Health Promot 1996;11(2):87-98.

42. Ajzen I. Attitudes, personality, and behavior. Chicago: Dorsey Press; 1988. ISBN 0256069352.

43. Rogers RW. A protection motivation theory of fear appeals and attitude change. J Psychol: Interdiscip Appl 1975;91(1):93-114. 
44. Bandura A. Social foundations of thought and action: a social cognitive theory. Upper Saddle River: Prentice-Hall, Inc; 1986. ISBN 013815614X.

45. Dijkstra A, De Vries H, Kok G, Roijackers J. Self-evaluation and motivation to change: social cognitive constructs in smoking cessation. Psychol Health 1999;14(4):42-5.

46. Dijkstra A, Sweeney L, Gebhardt W. Social cognitive determinants of drinking in young adults: beyond the alcohol expectancies paradigm. Addict Behav 2001;26(5):689-706.

47. Engels RCME, Wiers R, Lemmers L, Overbeek G. Drinking motives, alcohol expectancies, self-efficacy, and drinking patterns. J Drug Educ 2005;35(2):147-66.

48. Paulussen T, Kok G, Schaalma H. Antecedents to adoption of classroom-based AIDS education in secondary schools. Health Educ Res 1994;9(4):485-96.

49. Gottlieb NH, Goldstein AO, Flynn BS, Cohen JE, Bauman KE, Solomon LJ, et al. State legislators' beliefs about legislation that restricts youth access to tobacco products. Health Educ Behav 2003;30(2):209-24.

50. Eagly AH, Chaiken S. The psychology of attitudes. Orlando: Harcourt Brace Jovanovich College Publishers; 1993. ISBN 0155000977.

51. Suls J, Wills TA. Social comparison: contemporary theory and research. Hillsdale: Lawrence Erlbaum Associates, Inc; 1991. ISBN 0805805494.

52. Bandura A. Perceived self-efficacy in the exercise of control over AIDS infection. Eval Program Plann 1990;13(1):9-17.

53. Morrison I, Smith R. Hamster health care. BMJ 2001; 321(7276):1541-2.

54. Huby G, Porter M, Shaw J, Gerry M, McKinstry B, Wrate R. Morale among general practitioners: qualitative study exploring relations between partnership arrangements, personal style, and workload. BMJ 2002;325(7356):140.

55. Zantinge EM, Bensing JM, Kerssens JJ, Verhaak PFM. The workload of GPs: consultations of patients with psychological and somatic problems compared. Br J Gen Pract 2005; 55(517):609-14.

56. Gorgels WJMJ, Oude Voshaar RC, Mol AJJ, Van de Lisdonk EH, Van Balkom AJLM, Van den Hoogen HJM, et al. Discontinuation of long-term benzodiazepine use by sending a letter to users in family practice: a prospective controlled intervention study. Drug Alcohol Depend 2005;78(1):49-56.

57. Oude Voshaar RC, Gorgels WJMJ, Mol AJJ, van Balkom AJLM, Breteler M, Van de Lisdonk EH, et al. Predictors of relapse after discontinuation of long-term benzodiazepine use by minimal intervention: a 2-year follow-up study. Fam Pract 2003;20(4): $370-2$.

58. Niessen WJM, Haaijer-Ruskamp FM, Stewart RE, Broer J. Vermindering van gebruik van benzodizepinen door een brief van de eigen huisarts aan chronische gebruikers [Reduction in the consumption of benzodiazepines due to a letter to chronic users from their own general practitioner]. Ned Tijdschr Geneeskd 2005;149(7):356-61.

59. Cormack MA, Owens RG, Dewey ME. The effect of minimal interventions by general practitioners on long-term benzodiazepine use. J R Coll Gen Pract 1990;39(327):408-11.

60. Ten Wolde GB. Persoonlijk advies is effectiever. Individuele brief met stopadvies voor benzodiazepinen [Tailormade advice is more effective. Personalized letter with advice to quit benzodiazepines]. Pharm Weekblad 2004;139(49):1652-3.

61. Barclay S, Grande G, Wyatt P, Todd C, Finlay I. Not another questionnaire! Maximizing the response rate, predicting nonresponse and assessing non-response bias in postal questionnaire studies of GPs. Fam Pract 2002;19(1):105-11.

62. Swanborn PG. Basisboek sociaal onderzoek [Textbook social research]. Meppel: Boom; 2002. ISBN 9053527532.

63. Kenens RJ, Hingstman L. Human resources registers - registration GPs. Utrecht: Nivel; 2005.

64. Robinson G, Gould M. What are the attitudes of general practitioners towards research? Br J Gen Pract 2000;50(454):390-2. 